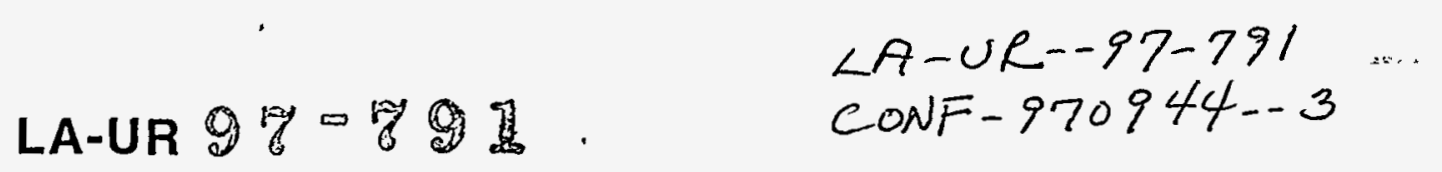

Title: QUANTIFICATION OF DAMAGE EVOLUTION FOR A MICROMECHANICAL MODEL OF DUCTILE FRACTURE IN SPALLATION OF TANTALUM

Author(s):
Presented at:
To be submitted to:

DISCLAIMER

This report was prepared as an account of work sponsored by an agency of the United States Government. Neither the United States Government nor any agency thereof, nor any of their employees, makes any warranty, express or implied, or assumes any legal liability or responsibility for the accuracy, completeness, or usefulness of any information, apparatus, product, or process disclosed, or represents that its use would not infringe privately owned rights. Reference herein to any specific commercial product, process, or service by trade name, trademark, manufacturer, or otherwise does not necessarily constitute or imply its endorsement, recommendation, or favoring by the United States Government or any agency thereof. The views and opinions of authors expressed berein do not necessarily state or reflect those of the United States Government or any agency thereor.
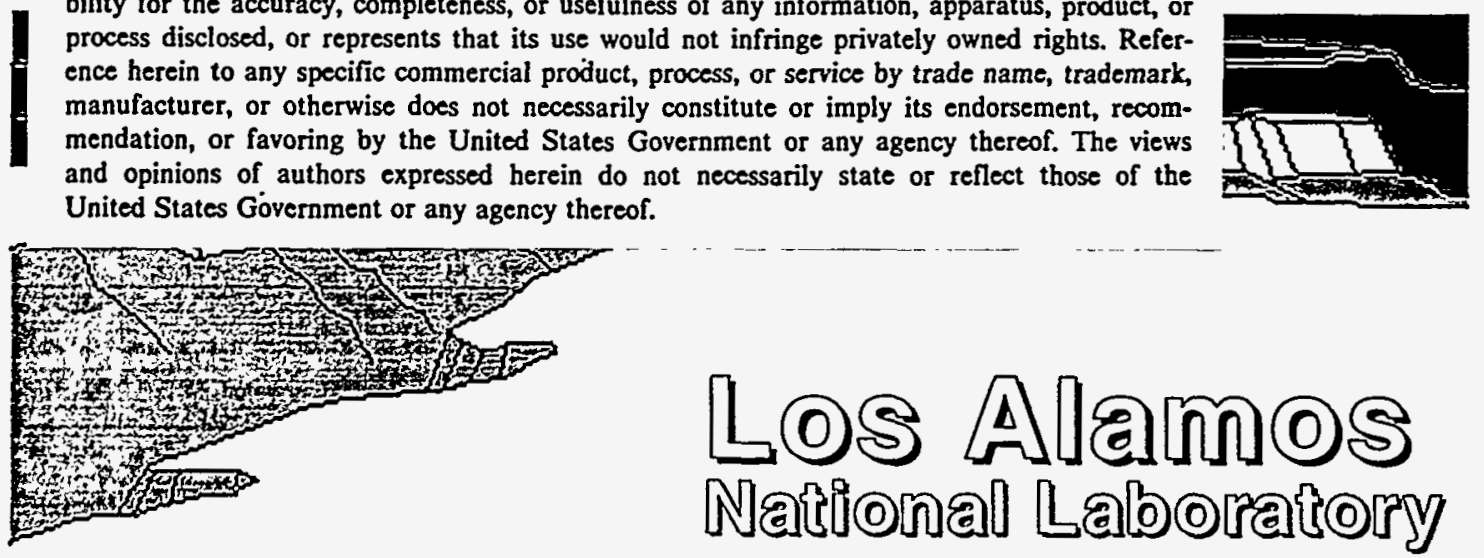

DISTRIBUTION OF THIS DOCUMENT IS UNLIMITED

Los Alamos National Laboratory, an affirmative action/equal opportunity employer, is operated by the University of California for the U.S. Department of Energy under contract W-7405-ENG-36. By acceptance of this article, the publisher recognizes that the U.S. Government retains a nonexciusive, royaltyree license to publish or reproduce the published form of this contribution, or to allow others to do so for U.S. Government purposes. The Los Alamos National Laboratory requests that the publisher Identify this article as work performed under the auspices of the U.S. Department of Energy.

This is a preprint of a paper intended for publication in a journal or proceedings. Because changes may be made before publication, this preprint is made avallable with the understanding that it will not be cited or reproduced without the permission of the author. 


\section{DISCLAIMER}

Portions of this document may be illegible in electronic image products. Images are produced from the best available. original document. 


\title{
Quantification of Damage Evolution for a Micromechanical Model of Ductile Fracture in Spallation of Tantalum
}

\author{
A. K. Zurek, W. R. Thissell, D. L. Tonks*, \\ R. Hixson** and F. Addessio*** \\ Materials Research \& Processing Science, *Nuclear Hydrodynamic Applications \\ **Detonation Science and Technology, ***Fluid Dynamics \\ Los Alamos National Laboratory \\ Los Alamos, NM 87545
}

\begin{abstract}
We present quantification of micromechanical features such as voids that comprise the ductile fracture obtained under uniaxial strain condition in a spall test of commercial purity tantalum. Two evolutionary parameters of ductile fracture void formation are quantified: (i) the void volume fraction (porosity) and its distribution with respect to the distance from the main spall fracture plane, and (ii) void diameter distribution. The results complement the discussion of the implications of void clustering and linking for micromechanical modeling of ductile fracture as presented in a paper by D. L. Tonks et al. in this volume.

Résumé. Nous présentons une quantification des caractéristiques micromécaniques décrivant la rupture ductile, tels les vides, en déformation uniaxiale obtenue lors d'un test d'écaillage sur du tantale de pureté commerciale. Nous décrivons l'évolution des vides jusqu'à la rupture par: (i) la fraction volumique de vide (porosité) et sa distribution en fonction de la distance par rapport au plan d'écaillage; et (ii) la distribution des diamètres des vides. Ces résultats complètent la discussion sur les implications de la coalescence des vides pour la modélisation micromécanique de la rupture ductile présentée par D.L. Tonks et al. lors de cette même conférence.
\end{abstract}

\section{INTRODUCTION}

Spallation is one of many experimental configurations that can produce controlled dynamic fracture for research purposes. Spallation is defined as a dynamic uniaxial strain fracture experiment. It occurs in a material due to tensile stresses generated by the interaction of two release (rarefaction) waves [1]. Ductile spallation is a process of damage accumulation and linkage which differs drastically from ductile fracture damage in the uniaxial tensile test by virtue of the stress state and the rate of damage accumalation. In the tensile test, voids are subject to a nearly uniaxial tensile stress field; homogeneous plastic strain dominates the flow process from the early stages. Due to the uniaxial deformation field the voids grow as elongated ellipsoids and the overall change in vicinity of failure is small, on the order of 5\%[2]. In contrast, in ductile spallation, voids are subject to extremely high, nearly isotropic, triaxial, and very localized hydrostatic stress fields. Void growth and coalescence dominate all stages of the damage process to a porosity of up to about $30 \%$ at the principal spall plane. Voids assume nearly spherical shapes due to the isotropic triaxial stress field. The growth rate of voids is very high and the void distribution is dictated by the large gradient in stress generated by the interaction of release waves. Porosity, void formation, growth, and coalescence therefore, are important variables in descriptions of spallation and the fracture criteria of the material $[1,3$, 4].

An impactor is launched at a stationary plate sample in a spallation plate impact experiment. Impact results in loading that induces a shock wave at the impact plane. The shock waves travel from the impact plane to the flyer plate back surface and the target back surface. Reflection of the waves occur at the free surfaces. The two release shock waves meet inside the sample to produce a region of tension. The sample will fail within this region and separate into two pieces if the amplitude of the tensile wave exceeds the spall strength of the material. Otherwise, the sample will develop an incipient deformation zone within this region with characteristic voids, cracks, and plastic deformation. In addition to the damage process the shock wave preceding spallation produces extensive shock hardening of the material and thus a reduction in the work hardening capacity.

The process of deformation and fracture can be investigated by using a "soft" sample recovery system and microscopic observation of the damage after the impact [1]. VISAR laser interferometry can be employed to record the back free surface velocity of the target $[5,6]$. Both techniques were utilized in this study of spallation properties of commercial-purity tantalum subjected to a peak shock pressure just below 
spallation. The reason for choosing this peak pressure was to obtain an incipient deformation zone to study evolving porosity, void formation and their distribution [7].

In this paper, two evolutionary parameters of ductile fracture void formation are quantified: (i) the porosity with respect to the distance from the main spall fracture plane and (ii) the statistical void diameter distribution. In a companion paper by D. L. Tonks et al. in this volume the implications of statistical void linking and coalescence to micromechanical modeling of ductile fracture are discussed.

A micromechanical model of spall is a theoretical analysis that attempts to explain, from more fundamental principles [8-11], the microscale interactions of voids which form complex fracture patterns (e.g., Figure 1). Quantification of parameters in a micromechanical model, in combination with wavepropagation and spall calculations, should lead to an improved explanation of observed spall signals in materials undergoing void nucleation, growth and coalescence under dynamic loading conditions.

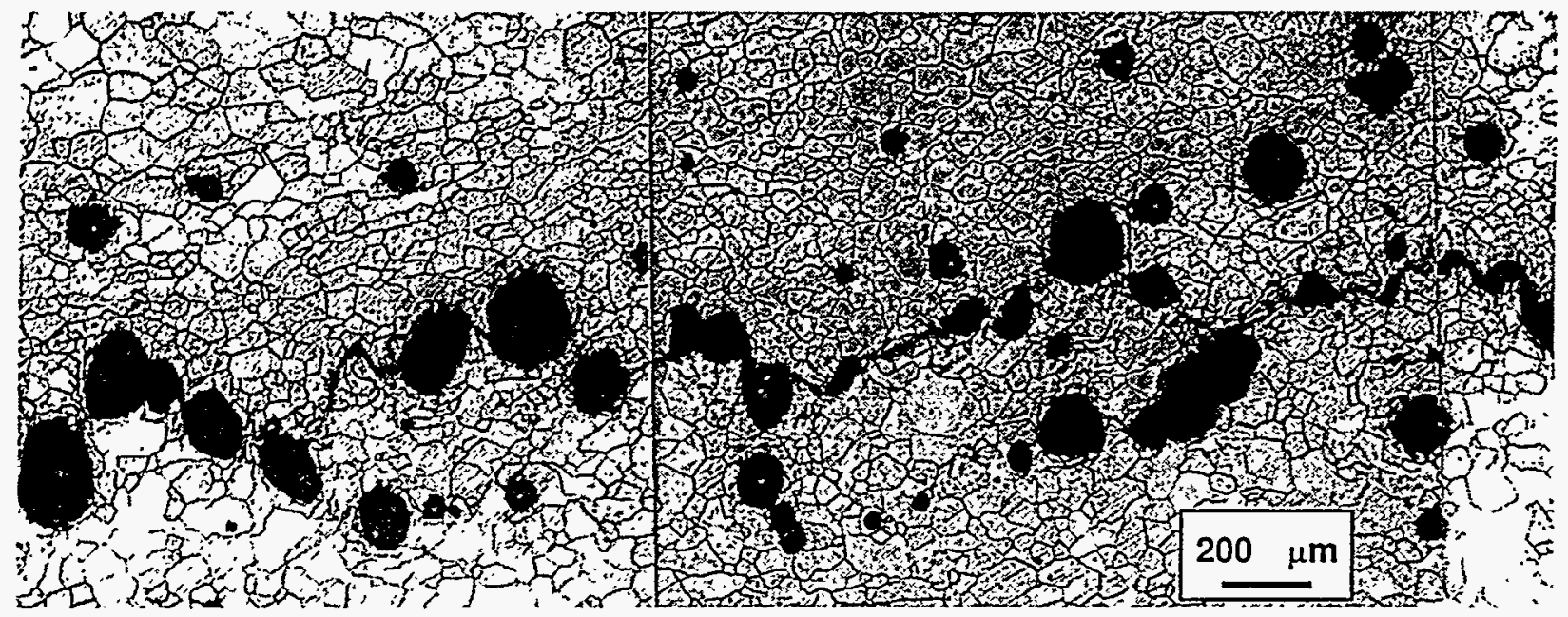

Figure 1: A fragment of ductile voids obtained in an incipient spall test of commercial purity tantalum (shock pressure $\sim 7.0$ $\mathrm{GPa}$ and shock duration $1 \mu \mathrm{s})$.

\section{MATERIAL AND EXPERIMENT DESCRIPTION}

In this study we used commercially pure (triple electron beam arc melted) unalloyed tantalum plate with a measured composition of $6 \mathrm{ppm}$ carbon, $24 \mathrm{ppm}$ nitrogen, $56 \mathrm{ppm}$ oxygen, $<1 \mathrm{ppm}$ hydrogen, $19 \mathrm{ppm}$ iron, $25 \mathrm{ppm}$ nickel, $9 \mathrm{ppm}$ chromium, $41 \mathrm{ppm}$ tungsten, $26 \mathrm{ppm}$ niobium, and the balance tantalum. The tantalum plate was in an annealed condition and had an equiaxed grain structure of $68 \mathrm{~mm}$ grain size [12].

\subsection{Spall Experiments}

We performed uniaxial strain spall tests utilizing an $80-\mathrm{mm}$ single-stage launcher and recovery techniques as previously described [1]. VISAR interferometry was used to record the free surface velocity of the samples $[5,6]$. A number of previous reports have described shock compression and release in metals including tantalum [13-19]. Tantalum's mode of failure and hence, spall strength are known to be a function of shock amplitude. Previous recovery and non-recovery spall tests reported a 5.2 GPa spall strength for a $6 \mathrm{GPa}$ shock amplitude, 7.3 GPa spall strength for a 9.5 GPa shock amplitude, and 3.0 to $4.5 \mathrm{GPa}$ spall strength for a $15 \mathrm{GPa}$ shock amplitude $[7,12,20]$. These spall strength values compare favorably with our results[21]. Tantalum samples for this investigation were spalled at $\sim 7.0 \mathrm{GPa}$ peak pressure and a $1 \mu$ s pulse duration under symmetric impact conditions in order to develop an incipient spall. Recovered spalled samples were analyzed using optical microscopy to characterize the fracture morphology.

\subsection{Microscopy}

The spall test of commercially pure tantalum performed at a $\sim 7.0 \mathrm{GPa}$ peak pressure developed an incipient spall. The cross section of the recovered, polished, and lightly etched [22] spall sample showed almost spherical voids running across the entire damaged area with multiple linking ranges connecting individual voids. Figure 1 shows a fragment of the cross section of the incipiently spalled sample used in the 
following analysis. There are two salient feature of the micrograph: (a) the voids are spherical due to the magnitude of the hydrostatic stresses and (b) the degree of porosity is large because the damage process is localized due to the severe stress gradients and high strain rate.

\subsection{Quantitative analysis}

Qualitative analytical descriptions of ductile fracture in spall were sufficient for most research purposes in the past. However, emerging models which try to describe ductile fracture are in need of quantitative parameters that would accurately describe evolutionary processes occuring during spall deformation leading to fracture. At present, most of the quantitative measurements of the crucial parameters that characterize ductile fracture (voids, void distribution, void linking ranges etc.) are possible using computer hardware and software. These measurements however, still require major interaction, decision making, and some pattern recognition help from the operator. The method described below was developed to quantify the deformation obtained in a spall test of tantalum.

\subsubsection{The two and three dimensional analysis}

Image Proß software was used for the two dimensional quantification of the voids of the spalled tantalum sample. The image acquisition system consists of a metallographic microscope fitted with a video camera connected to a computer through a frame grabber. Individual images were captured at $740 \times 480$ pixel resolution at 24 bits color. The analysis was performed on a montage of 10 image frames taken at $50 \mathrm{x}$ magnification which represent the entire sample cross section. The advantages of analyzing a montage over individual images are the great reduction of edge effects which are magnification dependent, and a number increase in analyzed features.

A WYKO RST-Plus $®$, an optical profilometry system, was used for depth measurements of individual voids. RST-Plus is an optical, non-contact, profilometry system that utilizes interferometric techniques [23]. The system consists of an optical microscope fitted with an interferometer, a video camera, and a computer control and acquisition system.

The Image Proß software allows us to identify voids and measure their location, size, aspect ratio, and the average diameter. This information, when combined with the data from the optical profilometry system that measures the depth of individual voids, gives us the three dimensional representation of the voids at the planar cut through the spalled samples.

\subsubsection{Assumptions and limitations}

Figure 2 shows a schematic representation of a metallographic cut through the spalled sample. The circles in this figure represent a two dimensional view of perfectly spherical, three dimensional voids.

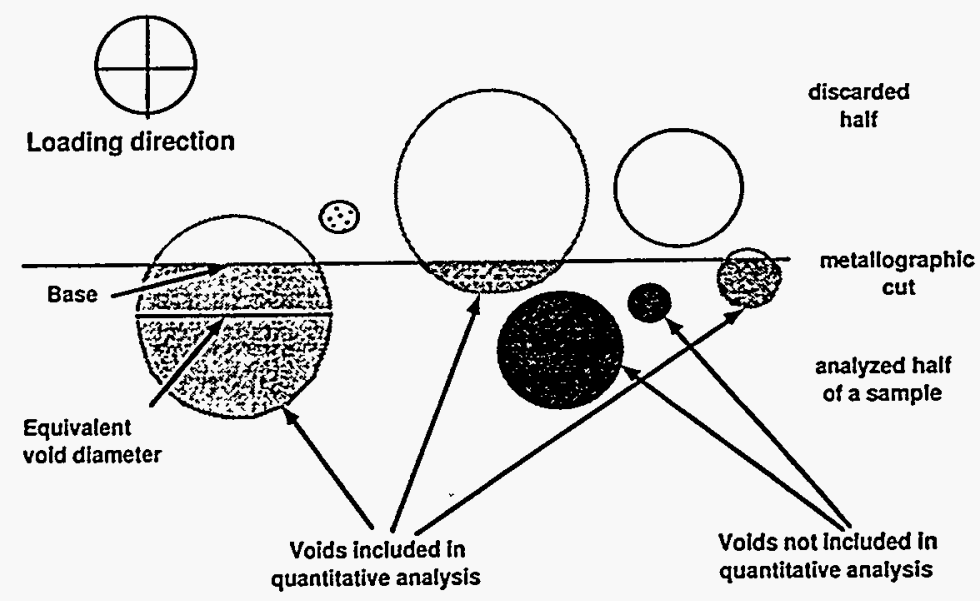

Figure 2: Schematic representation of a metallographic cut through the spalled sample. The circles in this figure represent the two dimensional view of the perfectly spherical, three dimensional voids. 
The main assumption we are making in our analysis of the measured data is that the voids are perfectly spherical, however we are able to measure the aspect ratio of the voids. In addition, on the metallographically cut surface (perpendicular to the plane of Figure 2), only those cross sections of the voids will be visible that come in contact with the cut surface. Voids present below the surface, regardless of their size, will not be included in the surface count of the quantitative analysis. In our test, the void size and their distribution change with the distance from the principal spall plane. As a result, the quantified total porosity, which we define as the fraction of void area at a statistically representative cut through the spall plane, may not be equivalent to the total fraction of void volume in the analyzed spalled sample. The total fraction of void volume in fact will be underestimated. We are assuming in our porosity analysis that the void fractional area at a planar cut is representative of their volume fraction. This has been shown analytically to be valid for the case of randomly distributed spheres of uniform size [24]. However, the void sizes are not uniform, but have a distribution.

The depth measurement of a void (using a RST-Plus) allows us to calculate its equivalent void volume, by reevaluating the void diameter (the base of a sphere) based on the relationship between its measured void depth and its area measured at the metallographic cut (using Image Pro). Therefore, the availability of three dimensional probing of the voids (their surface area and a corresponding depth) is invaluable. The assessment of $3 \mathrm{D}$ volumetric damage from $2 \mathrm{D}$ images is a problem of considerable richness. There are early references to this problem [24]. This and many others are summed in the Archive for History of Exact Sciences [25], [26] and a more recent treatment is available in [27].

There are additional limitations of our measurement technique arising from the need to use several different software packages to acquire the data and the need of operator help in decision making and in pattern recognition during the data collection process. Therefore, the data collection process may become tedious and time consuming when a large data set is required for statistical analysis.

\subsubsection{Analysis of the data.}

Figure 3 shows the porosity as a function of the distance from the spall plane, where the spall plane is defined as the plane of maximum porosity.

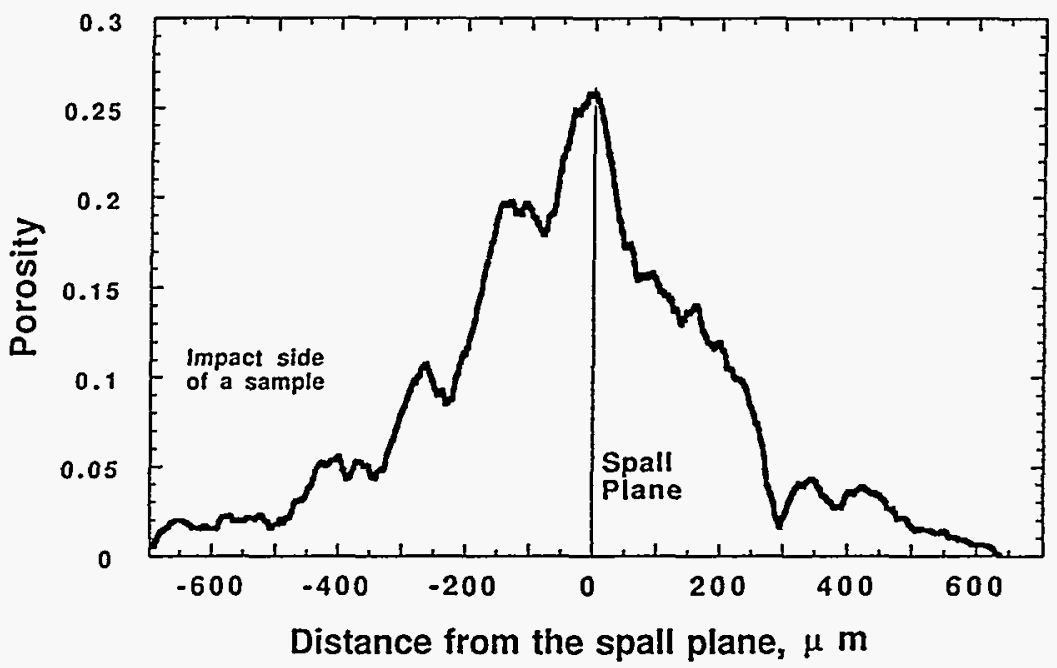

Figure 3: Change in porosity from the spall plane. Note the non-symmetrical porosity about the spall plane.

The porosity is defined here as a total void fractional area (the base of a spherical void) on the statistically random metallographic cut normal to the spall plane. There are several interesting findings resulting from this plot: (i) The porosity at the spall plane is about 0.26 . This result is in excellent agreement with the previously measured and predicted condition for fracture in a spall test as expressed in terms of critical porosity. Ductile fracture in spallation is preceded by a large increase in porosity. In the case of copper the porosity was 0.30 , at the fully spalled plane, as measured and predicted by [28] and [3], respectively. (ii) The porosity is not symmetrical with respect to the spall plane. When examining Figure 3 , we observe secondary peaks of porosity appearing regularly, approximately every $135 \mu \mathrm{m}$, on the left side of the spall plane, which in our test corresponds to the projectile side of a sample. We believe that this is evidence of an interaction of the release wave (initiated from the free surfaces of the large void clusters evolving at the principal spall plane) with the rarefaction wave. Multiple spall layers have been observed in 
metals subject to explosive loading $[29,30]$ and have been analyzed in terms of a dynamic void growth model [3]. However, the presence of periodic incipient spall planes in a flat-plate-impact recovery experiment, while a normal consequence of the coupling between void growth and wave propagation, is thought to be previously unobserved.

Figure 4(a) shows a distribution of the equivalent void diameters fitted to a log-normal density distribution function. From one metallographic cut, 322 voids, ranging in diameter from $14 \mu \mathrm{m}$ to $389 \mu \mathrm{m}$ were analyzed, and for graphing purposes all the data were consolidated into thirteen (13) - 25 microns wide bins. Figure $4(\mathrm{~b})$ is a cumulative percentage probability graph of measured void diameters using the equivalent void diameter and the void diameter (base) as indicated by a two dimensional metallographic image. The equivalent void diameter is the diameter of a void which corresponds to the three dimensional sphere representing a void. Figure 2 defines the equivalent void diameter and the void base.

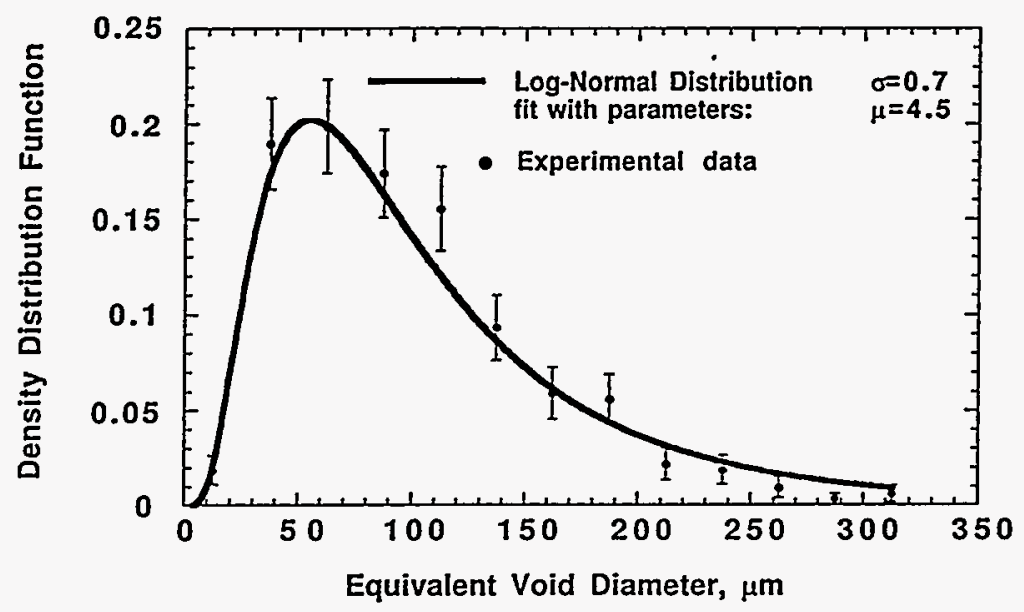

(a)

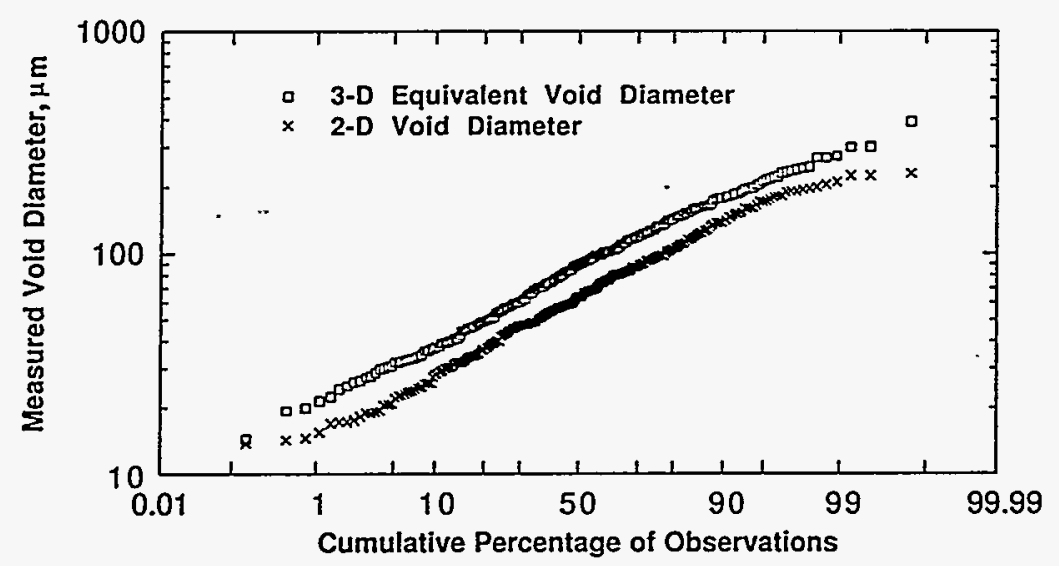

(b)

Figure 4: (a) Experimental data of the equivalent void diameter distribution fitted to the log-normal distribution function with parameters listed in the figure and $\chi^{2} /$ d.o.f. $=0.82$. (b) Comparison of equivalent void diameter based on three dimensional void measurements to void diameters as measured from a two dimensional metallographic cut shown as a cumulative percentage probability plot.

Figure 4(b) indicates that the equivalent void diameters are significantly larger than the two dimensional (base) void diameter. Both diameter distributions are well described by a straight line in Figure 4(b) within the limits imposed by the measurement method and size of the data set and therefore indicate that a lognormal description of the data is appropriate. The equivalent void diameter at the distribution function maximum (mode) is about $58 \mu \mathrm{m}$ in Fig. 4(a), while the median diameters are about 95 and $68 \mu \mathrm{m}$ (Fig. 4 (b)) for the equivalent void diameter and base void diameter, respectively.

\section{SUMMARY}

The current work gives a quantitative analysis of the damage accumulation process related to spallation. The results show that the spatial distribution of stress state and strain rate in shock loading are reflected in both the void shape and the distribution of voids observed in spallation. There are secondary maxima in porosity 
produced due to the complex reflection of the shock waves. The linkage of voids in the spall plane can be considered as the growth of damage in a highly shock hardened material under the action of high local triaxial stress. This results in localized linkage as discussed by [31]. It is significant to note that the local porosity levels achieved in spallation are much higher than in simple stress states such as uniaxial tension. This is because the values of the hydrostatic stress to flow stress ratio produce essentially local solid state cavitation processes rather than the distribution of extensive plastic strain which occurs in a conventional necking process. The important feature to be emphasized is that the quantitative assessment of both the level and the distribution of damage in spallation provides a method of linking experimental observations to existing models and to an eventually refinement of these models to encompass the physical description of variety of materials.

\section{Acknowledgments}

The authors want to thank Carl Trujillo for performing the spall test. David Embury and Jim Johnson are thanked for their comments and help in development of this project. This project is sponsored by the Joint DoD/ DOE Munitions Program.

\section{References}

[1] A. K. Zurek, J. N. Johnson, and C. E. Frantz, Journal de Physique, 49, C3, suppl. 9, (1988), 269.

[2] P. F. Thomason, Ductile Fracture in Metals, Pergamon Press, Oxford, 1990.

[3] J. N. Johnson, J. of Applied Physics, 52, 4, (1981), 2812.

[4] D. R. Curran, L. Seaman, and D. A. Shockey, Physics Reports, 147, (1987), 253.

[5] L. M. Barker and R. E. Hollenbach, J. Applied Physics, 43, 11, (1972), 4669.

[6] R. A. Graham and J. R. Asay, High Temperature - High Pressure, 10, (1978), 355.

[7] J. N. Johnson, R. S. Hixson, D. L. Tonks, et al., in Shock Compression of Condensed Matter, edited by S. C. Schmidt and W. C. Tao (AIP, New York, 1995), p. 523.

[8] D. L. Tonks, A. K. Zurek, and W. R. Thissell, in Metallurgical and Materials Applications of Shock-Wave and High-Strain-Rate Phenomena (EXPLOMET'95), edited by L. E. Murr, K. P. Staudhammer and M. A. Meyers (Elsevier, New York, 1995), p. 171.

[9] D. L. Tonks, J. de Physique, IV, C8, 4, (1994), 665.

[10] D. L. Tonks, in Dynamic Plasticity and Structural Behaviors, edited by S. Tanimura and A. S. Khan (Gordon and Breach, Luxembourg, 1995), p. 119.

[11] D. L. Tonks, in High-Pressure Shock Compression of Solids II (Dynamic Fracture and Fragmentation), edited by L. Davison, D. E. Grady and M. Shahinpoor (Springer-Verlag, New York, 1995), p. 237.

[12] G. T. Gray, III, in High-Pressure Science and Technology, edited by S. C. Schmidt, J. W. Shaner, G. A. Samara and M. Ross (AIP, 1994), p. 1103.

[13] J. N. Johnson and P. S. Lomdahl, J. de Physique, IV, Colloque C3, (1991), 223.

[14] J. N. Johnson, P. S. Lomdahl, and J. M. Wills, Acta Metallurgica, 39, (1991), 3015.

[15] J. N. Johnson, R. S. Hixson, G. T. Gray, III, et al., J. of Applied Physics, 72, (1992), 429.

[16] J. N. Johnson, in High Pressure Shock Compression of Solids, edited by J. R. Asay and M. Shahinpoor (Springer-Verlag, 1993), p. 217.

[17] J. N. Johnson, J. of Physics and Chemistry of Solids, 54, (1993), 691.

[18] J. N. Johnson, R. S. Hixson, D. L. Tonks, et al., in High Pressure Science and Technology-1993, edited by S. C. Schmidt, J. W. Shaner, G. A. Samara and M. Ross (American Institute of Physics, 1993), Vol. 309 , p. 1095.

[19] J. N. Johnson, in High Pressure Science and Technology-1993, edited by S. C. Schmidt, J. W. Shaner, G. A. Samara and M. Ross (American Institute of Physics, 1993), Vol. 309, p. 1145.

[20] G. T. Gray, III and A. D. Rollett, in High Strain Rate Behavior of Refractory Metals and Alloys, edited by R. Asfahani, E. Chen and A. Crowson (The Minerals, Metals and Materials Society, 1992), p. 303.

[21] A. K. Zurek, W. R. Thissell, J. N. Johnson, et al., Journal of Materials Processing Technology, 60, (1996), 261.

[22] A. M. Kelly, S. R. Bingert, and R. D. Reiswig, Microstructural Science, 23, (1996), 185.

[23] P. J. Caber, S. J. Martinek, and R. J. Niemann, in Proceedings of SPIE, edited by, 1993), Vol. , p. 2088.

[24] B. Cavalieri, Geometria Planara, 1653.

[25] K. Andersen, Archive for History of Exact Sciences, 31, 4, (1985), 291.

[26] A. A. Glagolev, Geometrical Methods, 1933.

[27] H. E. Exner, in Physical Metallurgy, edited by R. W. Cahn and P. Haasen (North-Holland, New York, 1996), Vol. II, p. 944.

[28] L. Seaman, T. W. Barbee Jr., and D. R. Curran, (Stanford Research Institute of Technology, 1971).

[29] C. L. Mader, T. R. Neal, and R. D. Dick, (University of California Press, Berkeley, 1980).

[30] J. S. Rinehart, J. Appl. Phys., 23, (1952), 1229.

[31] P. F. Thomason, in Recent Advances in Fracture, edited by R. K. Mahidhara, A. B. Geltmacher, P. Matic and K. Sadananda (The Minerals, Metals and Materials Society, Warrendale, Pennsylvania, 1997). 
PEER REVIEW

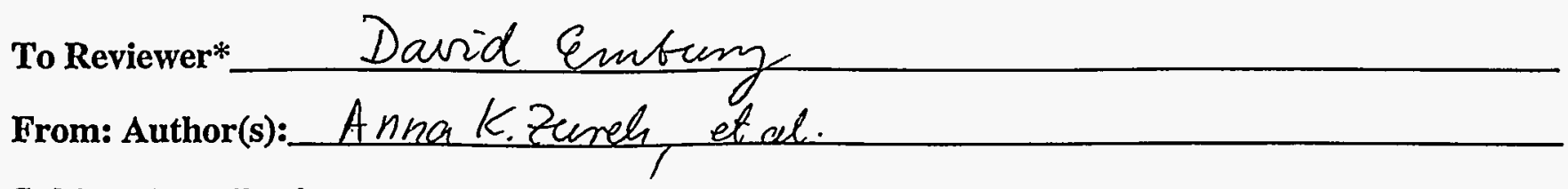
Subject: Peer Review

Title: Q Quantification of Daucage Evolution for Micromechourad Please review the attached manuscript to be published as a () LANL report, () Journal article, () other DY $M A T-97$, Proceidinge and return to me by

Please review this paper with as much care as you would give to a review for a high quality journal. Remember that the continued effectiveness of our peer review system is essential to maintaining the high standards that MST-5 has for its publications. Reviewing technical papers is an intellectual process that includes both subjective and objective elements. The reviewer must be objective in the sense of eliminating any personal bias he may have toward the subjective matter. At the same time the reviewer must evaluate a list of possible attributes, for the reviewer will almost always have some reactions that fall outside the scope of the guidelines given below. Nevertheless, the following list provides a minimal set of characteristics which should be evaluated.

1. Originality. Is the work sufficiently new to merit publication?

2. Significance. Is the work an important contribution to the field?

3. Completeness. The assumptions should be correct, the data valid, the scientific method sound, the conclusions adequately based on the data and theory.

4. Work of others + should be properly acknowledged.

5: Organization. The organization of the paper is extremely important of the reader is to understand the work. Ideas are most effectively communicated when there is a carefully planned and logical structure in the manuscript. The paper must be well written conform to recognize standards of literary style, and be readily understandable by engineers and scientists in the field.

6. Tables and figures Should be clear and compliment the text. The figures should be suitable for reproduction. Standard units should be used uniformly in the paper.

7. Overall clarity of the paper is extremely important; it cannot be overemphasized. A paper is written to convey ideas. to the reader and this will only be achieved when the author uses the right choice of words, effective sentence structures, correct spelling and punctuation, and paragraphing. Is the research objective clearly defined? Is the objective of the work met?

Please make your comments on a separate sheet. You may also mark the manuscript. Return the comments and the manuscript to the author. If you ate satisfied that the paper is suitable of republication, initial this peer review form. This form will accompany the draft during the line management approval process through the Division level.

Signature to indicate approval:_of

+The reviewer should recognize that LANL reports and journal articles are intended to serve different functions, so these criteria need to be applied in view of the intent of the paper.

*Two reviewers are required. They should be selected only after consultation with the section Leader. One reviewer should be outside the immediate section if possible. 
Date: Mon, 24 Feb 1997 16:17:40 -0700

To: Anna Zurek <zurek@lanl.gov>

From: jnj@lanl.gov (James N. Johnson)

X-Sender:jim@gridme.lanl.gov

Subject: Re: Dymat Paper

Anna, Here are some comments on the Dymat paper:

1. 2nd paragraph in introduction: next to last line; spelling - "proceeding"

2. Next to last line, bottom of p.1: implications (close up the s)

3. P. 2, third line down: "e.g., Figure 1" (drop s)

4. Section 2.3, last line: change to "localized due to severe stress gradients and high strain rates."

5. P. 4, first line. Second sentence might be changed to "The total fraction of void volume in fact will be underestimated." Drop the word "greatly."

6. P. 4, second paragraph, spelling - "considerable"

7. P. 6, ref. [17], J. of Physics and Chemistry of Solids, not Physica

This is all that I found in reading it over once. Overall this is a very good paper. This is the 1990s version of the work that SRI was doing on the quantification of void distributions in the 1970s. Modern techniques now make this much easier to do and to analyze. Figures 3 and 4 should be worth a small fortune to anyone trying to understand fracture in $\mathrm{Ta}$.

JIM J.

James N. Johnson

Group T-1, MS-B221

Los Alamos National Laboratory

Los Alamos, NM 87545 USA
PHONE: (505) 667-7580

FAX: (505) 665-5757

E-MAIL: jnj@lanl.gov 